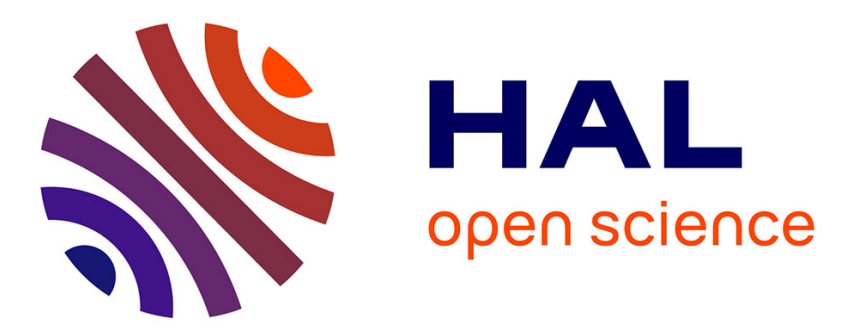

\title{
Sensitivity improvement of broadband electro-optic polymer-based optical phase modulator using 1D and 2D photonic crystal structures
}

Kevin Receveur, Kai Wei, Massinissa Hadjloum, Mohammed El Gibari, Alfredo de Rossi, Hong Wu Li, Afshin S. Daryoush

\section{To cite this version:}

Kevin Receveur, Kai Wei, Massinissa Hadjloum, Mohammed El Gibari, Alfredo de Rossi, et al.. Sensitivity improvement of broadband electro-optic polymer-based optical phase modulator using 1D and 2D photonic crystal structures. Chinese Optics Letters, 2017, 15 (1), pp.010003. 10.3788/COL201715.010003 . hal-01428657

\section{HAL Id: hal-01428657 https://hal.science/hal-01428657}

Submitted on 21 Jun 2018

HAL is a multi-disciplinary open access archive for the deposit and dissemination of scientific research documents, whether they are published or not. The documents may come from teaching and research institutions in France or abroad, or from public or private research centers.
L'archive ouverte pluridisciplinaire HAL, est destinée au dépôt et à la diffusion de documents scientifiques de niveau recherche, publiés ou non, émanant des établissements d'enseignement et de recherche français ou étrangers, des laboratoires publics ou privés. 


\title{
Sensitivity improvement of broadband electro-optic polymer-based optical phase modulator using 1D and 2D photonic crystal structures
}

\author{
K. Receveur ${ }^{1}$, K. Wei ${ }^{1}$, M. Hadjloum ${ }^{2}$, M. El Gibari ${ }^{2}$, A. De Rossi ${ }^{3}$, \\ H. W. Li ${ }^{2}$, and A. S. Daryoush ${ }^{1, *}$ \\ ${ }^{1}$ Department of ECE, Drexel University, Philadelphia, PA 19104 USA \\ ${ }^{2}$ IETR, Université Bretagne Loire, University of Nantes, 44322 Nantes, France \\ ${ }^{3}$ Thales Research and Technology France, 91767 Palaiseau, France \\ *Corresponding author: adaryoush@coe.drexel.edu \\ Received October 15, 2016; accepted December 6, 2016; posted online January 6, 2017
}

\begin{abstract}
This Letter introduces the design and simulation of a microstrip-line-based electro-optic (EO) polymer optical phase modulator $(\mathrm{PM})$ that is further enhanced by the addition of photonic crystal $(\mathrm{PhC})$ structures that are in close proximity to the optical core. The slow-wave $\mathrm{PhC}$ structure is designed for two different material configurations and placed in the modulator as a superstrate to the optical core; simulation results are depicted for both 1D and 2D PhC structures. The PM characteristics are modeled using a combination of the finite element method and the optical beam propagation method in both the RF and optical domains, respectively. The phase-shift simulation results show a factor of 1.7 increase in an effective EO coefficient (120 pm/V) while maintaining a broadband bandwidth of $40 \mathrm{GHz}$.
\end{abstract}

OCIS codes: 230.0230, 250.0250, 130.0130, 130.0250, 130.4110, 130.5296, 130.5460, 160.2100, 160.4236.

doi: 10.3788/COL201715.010003.

The combination of silicon photonics and electro-optic (EO) polymers in optical devices enables the fabrication of high-level photonic device integration [1] using CMOS compatible nanofabrication technology ${ }^{[2]}$. The use of EO polymers allows for a large EO coefficient $\left(r_{33}\right)$, very low dispersion, a fast response time $(<1 \mathrm{ps})$, and simple fabrication [3.4]. Compared to the limitations of traditional inorganic crystal modulators in terms of the $\mathrm{EO}$ coefficient $\left(r_{33} \sim 30 \mathrm{pm} / \mathrm{V}\right)$, the use of a synthesized EO polymer allows a higher EO coefficient ( $r_{33}=138 \mathrm{pm} / \mathrm{V}$ at $\left.1550 \mathrm{~nm}\right)$ due to the progress of chromophore synthesis and the high efficiency of poling; this improvement allows for a better modulation efficiency ${ }^{[5]}$ and extremely high modulation speeds of over $150 \mathrm{GHz}-[6$,$] . These benefits are crucial in cre-$ ating an efficient optical modulator design, either in terms of a realized phase or intensity $-[8-10]$ modulations. The high sensitivity of phase and intensity modulators has been crucial in various applications, such as opto-electronic oscillators $\underline{[1]}$ and optical deflectors in an all-optical analog to digital converter $\stackrel{[12]}{-}$.

Both the device length and driving voltage can be further reduced by introducing advanced modulator designs using a photonic crystal (PhC)-based slow-wave material. $\mathrm{PhC}$ materials exhibit slow-lightwave effects, which can be used to effectively increase the sensitivity of the EO index modulation $\underline{[13]}$. The ability to slow down the light passing through a modulator allows for a reduced group velocity, as the lightwave is traveling through the material. The slow lightwave in $\mathrm{PhC}$ materials enhances the in-device phase shifts and creates an even more efficient phase modulation ${ }^{[14]}$. Modulators using $\mathrm{PhC}$ materials have been explored using a combination of ceramic-air materials $\frac{[15]}{}$ as well as
ceramic-EO polymer $\mathrm{PhC}$ structures ${ }^{[16]}$. In recent years, studies have focused on EO polymers in combination with silicon $1 \mathrm{D}$ and $2 \mathrm{D} \mathrm{PhC}$ waveguides $\underline{[17,18]}$, which greatly improve the effective EO coefficient of the modulator design. The majority of recent modulator designs use a lateral modulator design; however, a vertical design using $\mathrm{PhC}$ is yet to be explored. This design with $\mathrm{PhC}$ requires more manufacturing sensitivity and also introduces challenge to fabricate air gaps inside a $\mathrm{PhC}$ material.

This Letter introduces the performance improvement of the EO polymer-based vertical phase modulator design using integrated $1 \mathrm{D}$ and $2 \mathrm{D} \mathrm{PhC} \mathrm{structures} \mathrm{to} \mathrm{a} \mathrm{microstrip}$ transmission line. The addition of $\mathrm{PhC}$ will enhance the effective EO coefficient to improve the optical phase modulation sensitivity by slow-wave $\mathrm{PhC}$ structures. The addition of the $\mathrm{PhC}$ material as either a superstrate above the optical core or a substrate below the optical core produces an improved modulator figure of merit for a broad bandwidth of operation up to $40 \mathrm{GHz}$.

The vertical modulator topology, shown in Fig. 1 , is induced by placing two copper electrodes on the top and bottom of a substrate material. Between the two electrodes, an optical core made out of an EO polymer (CPO-1) using polymethyl methacrylate (PMMI) as a host material $\left(n=1.63, \varepsilon_{r}=3.15, \tan \delta<10^{-2}\right)$ is placed surrounded by the cladding material, Norland Optical Adhesive 65, or NOA65 $\left(n=1.51, \varepsilon_{r}=3.2, \tan \delta=2.2 \times 10^{-2}\right)$, an optical adhesive cured by UV light. The optical core was chosen to be $a=1.6 \mu \mathrm{m}$ and $b=1.6 \mu \mathrm{m}$, confining the wave to a single TEM-like mode beyond $1400 \mathrm{~nm}$. The thickness of the electrodes was chosen to be $2 \mu \mathrm{m}$. The height of the NOA65 material and the width of the 


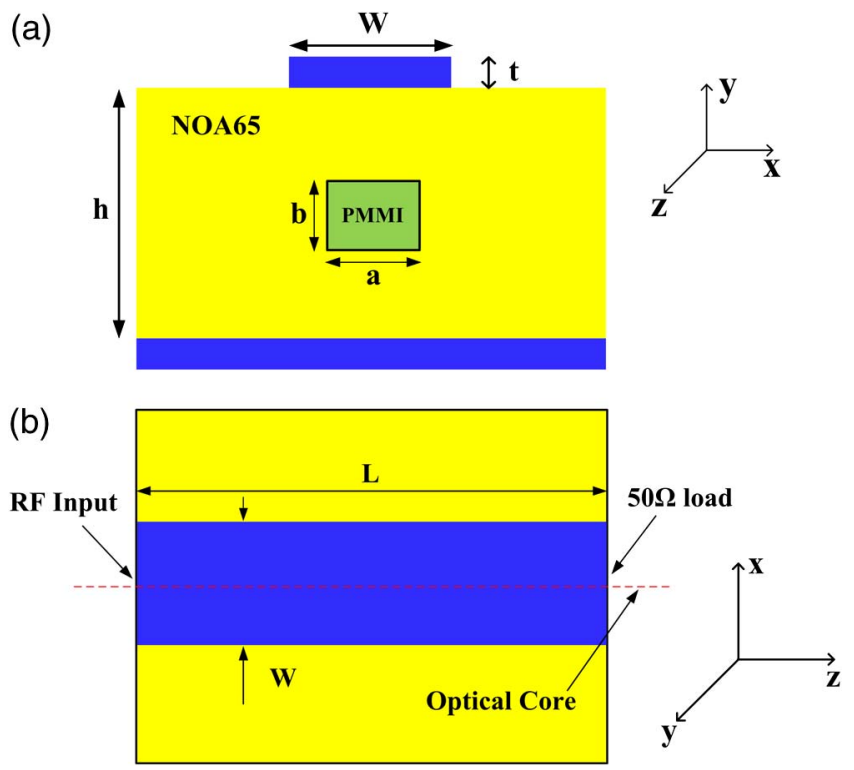

Fig. 1. Conceptual overview of a baseline EO polymer-based traveling-wave optical phase modulator design; (a) $X-Y$ cross section, and (b) $X-Z$ cross section.

top $\mathrm{Cu}$ electrode are determined to match the microstrip $\mathrm{RF}$ transmission line to a characteristic impedance $\left(Z_{0}\right)$ of $50 \Omega$, reducing $\mathrm{RF}$ dispersion characteristics and mismatch-induced losses over the phase modulator length, $L$, of $1 \mathrm{~cm}$.

The RF characteristics of the modulator, shown in Fig. 2, were simulated using the finite element method $(\mathrm{FEM})$ with a commercial product, HFSS $\stackrel{[19]}{ }$. The substrate height, $h$, was optimized to $12 \mu \mathrm{m}$ with an electrode width of $w=27 \mu \mathrm{m}$. This attained a characteristic impedance of $50.8 \Omega$ with a 3 -dB RF attenuation bandwidth of $42.5 \mathrm{GHz}$ for a $1 \mathrm{~cm}$ long phase modulator design. Optical wave simulations were performed using the beam propagation method (BPM) through use of the OptiBPM commercial software 20$]$.

For each simulation, the EO coefficient of the polymer was selected to be $70 \mathrm{pm} / \mathrm{V}$. The modulator figure of merit, $V_{\pi} \times L$, was determined to be $6.5 \mathrm{~V} \cdot \mathrm{cm}$ with an optical loss of $1.8 \mathrm{~dB} / \mathrm{cm}$. The effective $r_{33}$ of the modulator was then determined to be $68.7 \mathrm{pm} / \mathrm{V}$ from $\underline{[8]}$

$$
r_{33 \mathrm{eff}}=\frac{\lambda_{0} h}{2 n_{\mathrm{opt}}^{3} \Gamma V_{\pi} L} .
$$

Designs of the 1D and 2D PhC structures are conducted using the plane wave expansion (PWE) method using the FEM for verification in 3D in the HFSS. Two topologies of $\mathrm{PhC}$ were selected: the first one uses a varying dielectric of a PMMI/EO polymer and $\mathrm{Si}_{3} \mathrm{~N}_{4}(n=2.46)$, and the second one uses a combination of a PMMI/EO polymer and air gaps within the material in order to compare two slowwave structure models. $\mathrm{Si}_{3} \mathrm{~N}_{4}$ was selected due to its close refractive index value to the one for the core material. The latter topology is very popular with lateral phase modulators but is impractical for vertical topologies. The first
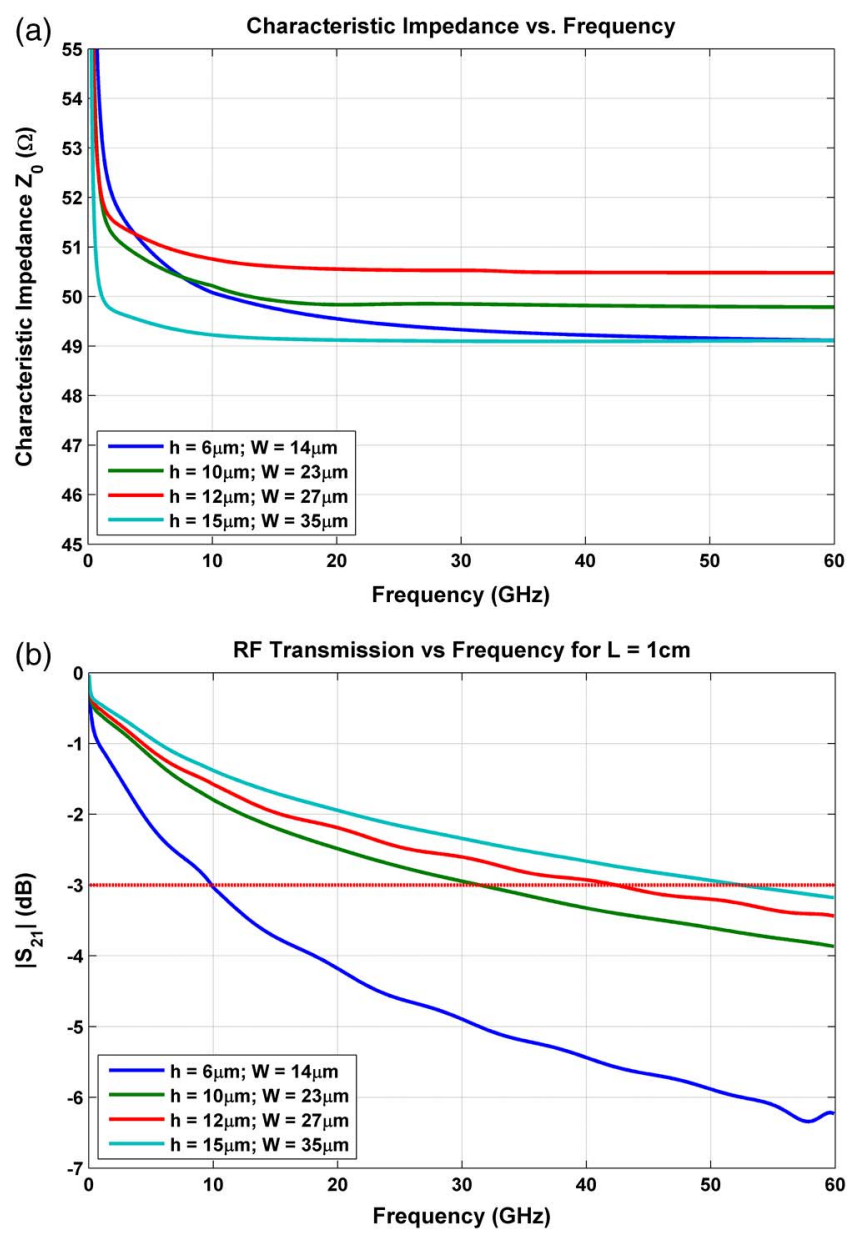

Fig. 2. Performance of $50 \Omega$ microstrip-line traveling-wave structure versus the frequency for various substrate heights: (a) dispersion of characteristic impedance, and (b) RF insertion loss over $1 \mathrm{~cm}$ length.

topology is reported here, and it is considered for both superstrate and substrate formats.

The 1D structure material design consists of a base material of PMMI/EO polymer, with a substrate width $d$, of either air gaps or $\mathrm{Si}_{3} \mathrm{~N}_{4}$. The total periodicity of the material is determined by $a$. For the PMMI/ $\mathrm{Si}_{3} \mathrm{~N}_{4}$ combination [Fig. 3(a)], the periodicity was selected as $318 \mathrm{~nm}$ with an $\mathrm{Si}_{3} \mathrm{~N}_{4}$ layer width of $192 \mathrm{~nm}$. The region of operation was chosen as very close to the band edge of the material, utilizing the slow light produced by the periodic $\mathrm{PhC}$ material. The slowness characteristics of the material are shown in Fig. 3(b) through the percent change in the group index of the material. This change in the group index indicates a slowdown in the group velocity of the wave. This change in group index for the PMMI/ $\mathrm{Si}_{3} \mathrm{~N}_{4}$ material at $1550 \mathrm{~nm}$ was determined to be $28 \%$ for the above periodicity.

The 2D structure material design consists of a base material of a PMMI/EO polymer surrounding periodic cylinders made out of an $\mathrm{Si}_{3} \mathrm{~N}_{4}$ material. The design parameters consist of the cylinder radius, $d$, and the periodicity between holes, $a$. For the PMMI/ $\mathrm{Si}_{3} \mathrm{~N}_{4}$ combination [Fig. 4(a)], the periodicity was selected as $384 \mathrm{~nm}$ 

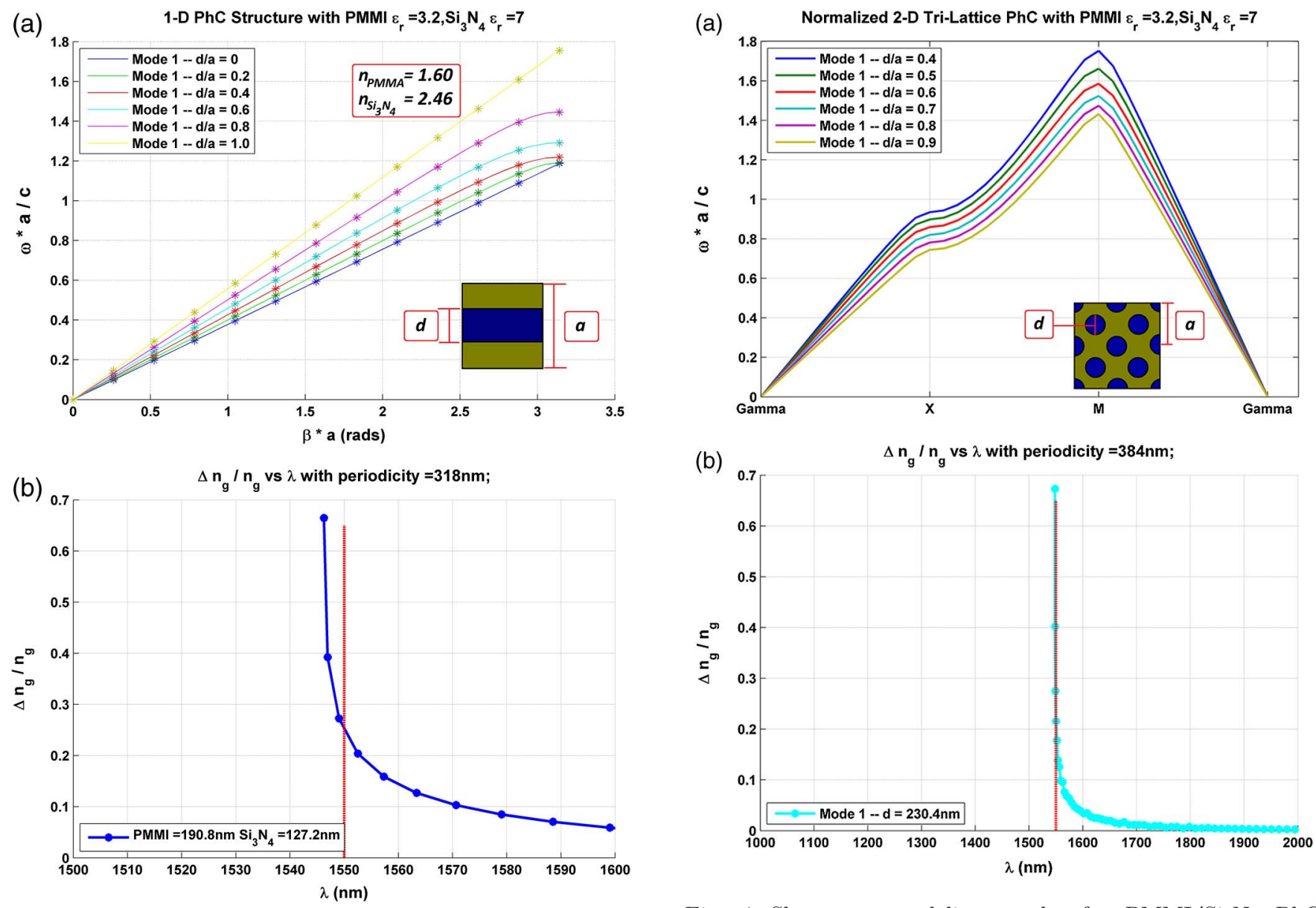

Fig. 3. Slow-wave modeling results for $\mathrm{PMMI} / \mathrm{Si}_{3} \mathrm{~N}_{4} \mathrm{PhC}$ material: (a) Normalized dispersion diagram of $1 \mathrm{D} \mathrm{PhC}$ using varying dielectric of $\mathrm{PMMI} / \mathrm{Si}_{3} \mathrm{~N}_{4}$ material with $a$ as the $\mathrm{PhC}$ periodicity and $d$ as the $\mathrm{Si}_{3} \mathrm{~N}_{4}$ layer thickness. (b) Change in group index relative to the operating wavelength for $a=318 \mathrm{~nm}$ and $d=192 \mathrm{~nm}$. The red line represents the performance at $\lambda=1550 \mathrm{~nm}$.

with an $\mathrm{Si}_{3} \mathrm{~N}_{4}$ hole diameter of $230 \mathrm{~nm}$. The slowness characteristics of the material are shown in Fig. 4(b) through the percent change in the group index of the material. Similarly for the PMMI/ $\mathrm{Si}_{3} \mathrm{~N}_{4}$ 1D structure, the increased group index results in the reduced group velocity of the lightwave. A $51 \%$ change in the group index was determined for a periodic PMMI/ $\mathrm{Si}_{3} \mathrm{~N}_{4}$ material at $1550 \mathrm{~nm}$.

To incorporate a slow-wave effect inside the baseline modulator, the $\mathrm{PhC}$ structures were placed as either a superstrate [Fig. $\underline{5(\mathrm{a})}$ ] or a substrate design. Similar to Fig. 5(a), the $\mathrm{PhC}$ material interacts with optical waves in the optical core by placing it below instead of above. A buffer layer of NOA65 is placed above or below the core to control the interactions between the optical core and the $1 \mathrm{D}$ or $2 \mathrm{D} \mathrm{PhC}$ while mitigating optical losses. The slow-wave structure was simulated using a combination of FEM and BPM modeling to determine the optical characteristics as a wave was injected into the modulator.

The zoomed-in details of the optimized design using 1D and 2D PhC dimensions are shown in Fig. $\underline{5(\mathrm{~b})}$ and $\underline{5(\mathrm{c})}$,

Fig. 4. Slow-wave modeling results for $\mathrm{PMMI} / \mathrm{Si}_{3} \mathrm{~N}_{4} \mathrm{PhC}$ material: (a) Normalized dispersion diagram of $2 \mathrm{D} \mathrm{PhC}$ using varying dielectric of $\mathrm{PMMI} / \mathrm{Si}_{3} \mathrm{~N}_{4}$ material with $a$ as the $\mathrm{PhC}$ periodicity and $d$ as the $\mathrm{Si}_{3} \mathrm{~N}_{4}$ hole diameter. (b) Change in group index relative to the operating wavelength for $a=384 \mathrm{~nm}$ and $d=230 \mathrm{~nm}$. The red line represents the performance at $\lambda=1550 \mathrm{~nm}$.

respectively, where the optimum width and thickness of $1.6 \mu \mathrm{m}$ and $500 \mathrm{~nm}$ for the $\mathrm{PhC}$ were determined by the tradeoff between the figure of merit $\left(V_{\pi} \times L\right)$ and the optical loss within the core through consecutive modeling. An optimum cladding/buffer layer was also determined in a similar modeling manner to be $500 \mathrm{~nm}$. The original modulator length was shortened to $300 \mu \mathrm{m}$ in order to have a higher resolution for each BPM node and for computational efficiency. An equivalent driving voltage of $400 \mathrm{~V}$ for $300 \mu \mathrm{m}$ (rather than $12 \mathrm{~V}$ for $1 \mathrm{~cm}$ ) was applied to the modulator electrodes to observe the phase change within this short device. The $V_{\pi}$ value was determined by the amount of voltage it takes to shift the phase of the modulator by $\pi \mathrm{rad}$. This value is then multiplied by the modulator length, $L$, to find the phase modulator figure of merit.

It is shown in Fig. $6(\mathrm{a})$ and $6(\mathrm{~b})$ that the phase change increases as the periodicity approaches the theoretical value. Employing this change in periodicity, the $V_{\pi}$ value can be optimized. Using the $1 \mathrm{D} \mathrm{PMMI} / \mathrm{Si}_{3} \mathrm{~N}_{4}$ superstrate case, the modulator figure of merit was determined to be $3.36 \mathrm{~V} \cdot \mathrm{cm}$ at a periodicity $a$ of $318 \mathrm{~nm}$, while using the 


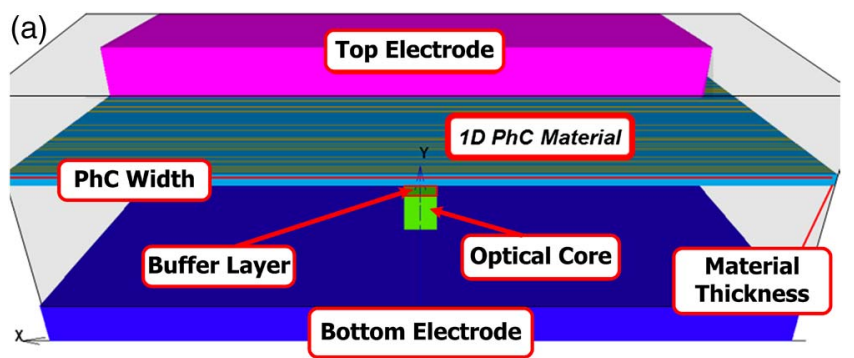

(b)

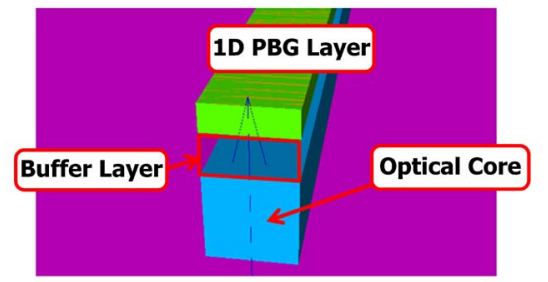

(c)

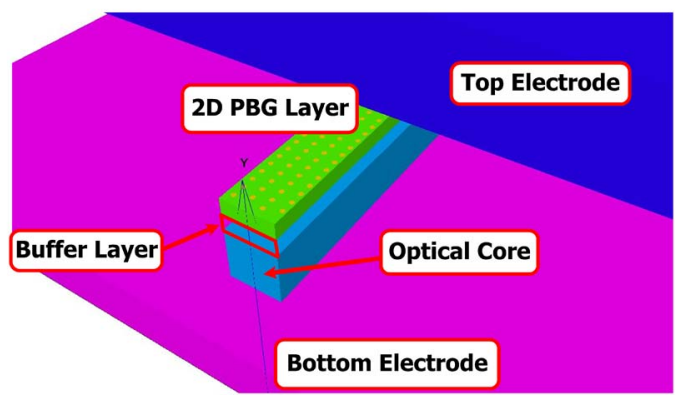

Fig. 5. Improved phase modulator design and results using a 1D or $2 \mathrm{D} \mathrm{PhC} \mathrm{superstrate} \mathrm{as} \mathrm{a} \mathrm{slow} \mathrm{wave:} \mathrm{(a)} \mathrm{cross-sectional} \mathrm{view} \mathrm{of}$ a phase modulator, (b) zoomed-in view of $1 \mathrm{D} \mathrm{PhC}$ layer as a superstrate to the optical core with $\mathrm{PhC}$ width $=1.6 \mu \mathrm{m}$, $\mathrm{PhC}$ thickness $=500 \mathrm{~nm}$, and a buffer layer of $500 \mathrm{~nm}$, and (c) zoomed-in view of $2 \mathrm{D} \mathrm{PhC} \mathrm{layer} \mathrm{as} \mathrm{a} \mathrm{superstrate} \mathrm{to} \mathrm{the} \mathrm{op-}$ tical core with $\mathrm{PhC}$ width $=1.6 \mu \mathrm{m}, \mathrm{PhC}$ thickness $=500 \mathrm{~nm}$, and a buffer layer of $500 \mathrm{~nm}$.

2D PMMI/ $/ \mathrm{Si}_{3} \mathrm{~N}_{4}$ superstrate case, the figure of merit $\left(V_{\pi} \times L\right)$ was simulated to be $2.41 \mathrm{~V} \cdot \mathrm{cm}$ at a periodicity $a$ of $360 \mathrm{~nm}$.

The effective EO coefficient $r_{33 \mathrm{eff}}$ is then calculated using Eq. (1), where $\lambda=1550 \mathrm{~nm}, h=12 \mu \mathrm{m}, n_{\mathrm{opt}}=1.6$, $L=300 \mu \mathrm{m}$, and $\Gamma=0.9$. In Fig. 6(c), the effective EO coefficient for the PMMI/Si $\mathrm{N}_{3}$ case was then determined to be $104.9 \mathrm{pm} / \mathrm{V}$, whereas in Fig. 6(d), the EO coefficient for the $2 \mathrm{D} \mathrm{PMMI} / \mathrm{Si}_{3} \mathrm{~N}_{4}$ case was determined to be $146.1 \mathrm{pm} / \mathrm{V}$, which improves the modulator EO coefficient by about a factor of 1.5 and 2.1, respectively, compared to the baseline traveling-wave design without $\mathrm{PhC}$.

The superstrate results were evaluated in a similar manner. By comparing the velocity mismatch between the group index of the optical and RF waves, the bandwidth of each modulator design is limited by the RF attenuation to $40 \mathrm{GHz}$, while an improved figure of merit is observed for the modulator. Adding a $\mathrm{PhC}$ in the superstrate or substrate, however, warrants unwanted losses from the $\mathrm{PhC}$ structure in addition to manufacturing challenges. For the superstrate case, the total optical losses through the $1 \mathrm{D}$ and $2 \mathrm{D} \mathrm{PMMI} / \mathrm{Si}_{3} \mathrm{~N}_{4} \mathrm{PhC}$ designs were simulated as 4.6 and $4.0 \mathrm{~dB} / \mathrm{cm}$, respectively, compared to

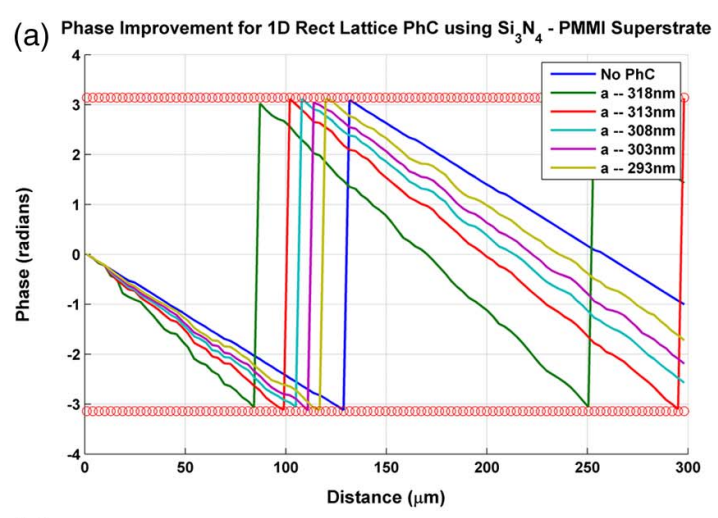

(b) Phase Improvement for $2 \mathrm{D}$ Tri Lattice PhC using $\mathrm{Si}_{3} \mathrm{~N}_{4}-\mathrm{PMMI}$ Superstrate

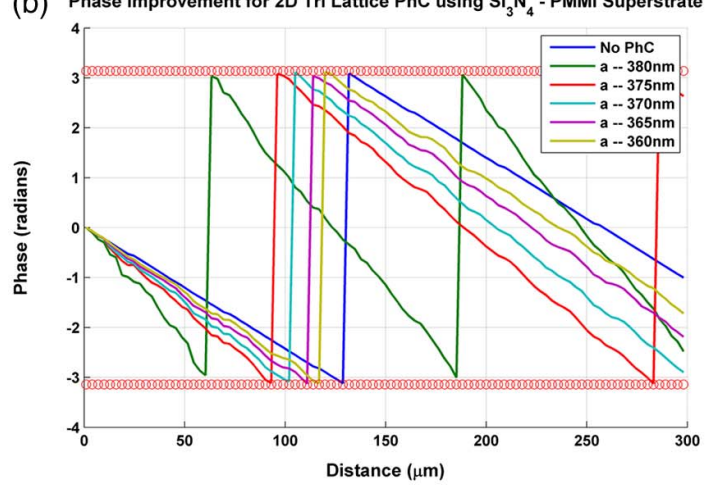

(C) Effective EO coefficient for $1 \mathrm{D}$ Rect Lattice PhC using $\mathrm{Si}_{3} \mathrm{~N}_{4}-\mathrm{PMMI}$ Superstrate

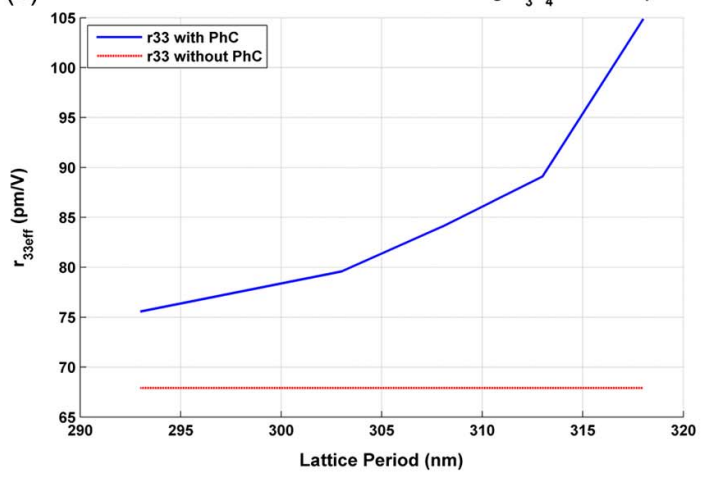

(d) Effective EO coefficient for $2 \mathrm{D}$ Tri Lattice $\mathrm{PhC}$ using $\mathrm{Si}_{3} \mathrm{~N}_{4}-\mathrm{PMMI}$ Superstrate

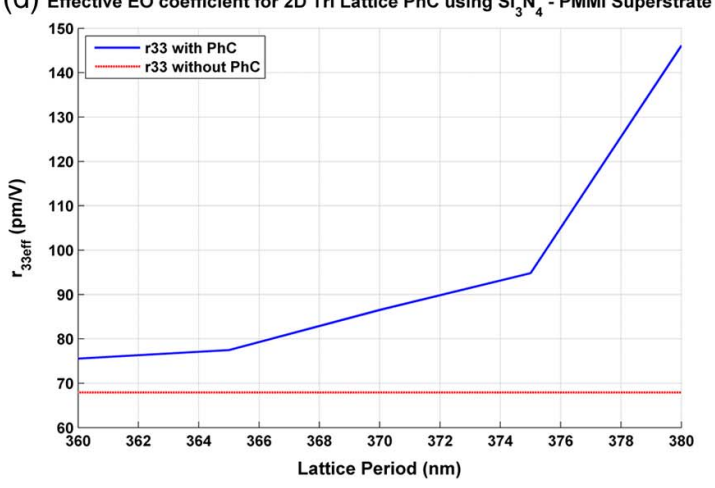

Fig. 6. (a) The wrapped-around achieved phase variation as a function of the phase modulator with and without $1 \mathrm{D} \mathrm{PhC}$ slow-wave structures of $\mathrm{PMMI} / \mathrm{Si}_{3} \mathrm{~N}_{4}$, (b) the wrapped-around achieved phase variation as a function of the phase modulator with and without $2 \mathrm{D} \mathrm{PhC}$ slow-wave structures of $\mathrm{PMMI} / \mathrm{Si}_{3} \mathrm{~N}_{4}$, (c) effective $\mathrm{EO}$ coefficient based on the optimum periodicity $a$, $318 \mathrm{~nm}$, of the 1D PMMI/ $\mathrm{Si}_{3} \mathrm{~N}_{4}$ PhC lattice, and (d) effective EO coefficient based on the optimum periodicity $a, 360 \mathrm{~nm}$, of the $2 \mathrm{D} \mathrm{PMMI} / \mathrm{Si}_{3} \mathrm{~N}_{4} \mathrm{PhC}$ lattice. 
Table 1. Performance Comparison of Various Phase Modulator Design Topologies Using Superstrate and Substrate 1D PhC

\begin{tabular}{lcc}
\hline Superstrate & $\begin{array}{c}1 \mathrm{D} \\
\mathrm{PMMI} / \mathrm{Si}_{3} \mathrm{~N}_{4}\end{array}$ & $\begin{array}{c}2 \mathrm{D} \\
\mathrm{PMMI} / \mathrm{Si}_{3} \mathrm{~N}_{4}\end{array}$ \\
\hline$V_{\pi} \times L(\mathrm{~V} \cdot \mathrm{cm})$ & 3.36 & 2.41 \\
$r_{33 \text { eff }}(\mathrm{pm} / \mathrm{V})$ & 104.9 & 146.1 \\
Optimal Periodicity & 318 & 360 \\
$(\mathrm{~nm})$ & & \\
$\alpha(\mathrm{dB} / \mathrm{cm})$ & 4.6 & 4.0 \\
\hline & $1 \mathrm{D}$ & $2 \mathrm{D}$ \\
Substrate & ${\mathrm{PMMI} / \mathrm{Si}_{3} \mathrm{~N}_{4}}$ & ${\mathrm{PMMI} / \mathrm{Si}_{3} \mathrm{~N}_{4}}$ \\
\hline$V_{\pi} \times L(\mathrm{~V} \cdot \mathrm{cm})$ & 3.26 & 2.38 \\
$r_{33 \mathrm{eff}}(\mathrm{pm} / \mathrm{V})$ & 108.4 & 147.8 \\
Optimal Periodicity & 318 & 360 \\
$(\mathrm{~nm})$ & & \\
$\alpha(\mathrm{dB} / \mathrm{cm})$ & 5.2 & 4.8 \\
\hline
\end{tabular}

$1.8 \mathrm{~dB} / \mathrm{cm}$ in the original structure. Results for all considered topologies are summarized in Table 1 .

Compared to the characteristics of the baseline modulator design with $V_{\pi} \times L=6.5 \mathrm{~V} \cdot \mathrm{cm}$ (i.e., $r_{33}=$ $68.7 \mathrm{pm} / \mathrm{V})$, each of the designs offered at least $60 \%$ improvement in the figure of merit $V_{\pi} \times L$, which effectively increased by $60 \%$ the resulting "effective" EO coefficient.

In conclusion, this Letter demonstrates realistic fullwave modeling of an EO polymer-based vertical realization of an optical phase modulator design, where its phase modulation sensitivity is enhanced by $1 \mathrm{D}$ or $2 \mathrm{D} \mathrm{PhC}$ structures. Enhancement of the phase modulator response is due to the slow-wave effect in $1 \mathrm{D}$ and $2 \mathrm{D} \mathrm{PhC} \mathrm{struc-}$ tures. This enhancement is quantified by comparison of the device figure of merit of $V_{\pi} \times L=3.26 \mathrm{~V} \cdot \mathrm{cm}$ for a $\mathrm{PMMI} / \mathrm{Si}_{3} \mathrm{~N}_{4}$ substrate to $6.5 \mathrm{~V} \cdot \mathrm{cm}$ for the baseline bulk design; hence, improved EO is attained by nearly doubling the coefficient with an RF bandwidth of $40 \mathrm{GHz}$.

The superstrate and substrate designs evaluated offer an improvement over the baseline bulk phase modulator to different degrees of effective EO coefficient; however, the optical loss increases with the new structure. The 2D $\mathrm{PMMI} / \mathrm{Si}_{3} \mathrm{~N}_{4} \mathrm{PhC}$ combination offers a better improvement in the figure of merit and relative optical loss characteristics with an optical wave confinement of the first mode to the PMMI/EO polymer portion of the PhC. Numerical calculations and performance simulations of $1 \mathrm{D}$ and $2 \mathrm{D}$ $\mathrm{PhC}$ using a PMMI/air combination are also performed but not reported here; even though it seems to be more effective in its phase modulation efficiency, the PMMI/ $\mathrm{Si}_{3} \mathrm{~N}_{4}$ results are more practical in terms of fabrication process, since there is no access to the modulators from the top in the vertical topologies when the placement of air gaps cannot be realized, as compared to the lateral modulator designs. In addition, the fabrication of a $\mathrm{PhC}$ substrate layer allows for more variability during the microfabrication process steps and should be avoided. A lateral design is also being considered to employ an efficient MachZehnder intensity modulator, where an RF injection method and optical mode converter are required for various applications, such as opto-electronic oscillators $\underline{[1,21]}$.

\section{References}

1. J. Leuthold, C. Koos, W. Freude, L. Alloatti, R. Palmer, D. Korn, J. Pfeifle, M. Lauermann, R. Dinu, S. Wehrli, M. Jazbinsek, P. Günter, M. Waldow, T. Wahlbrink, J. Bolten, H. Kurz, M. Fournier, J. M. Fedeli, H. Yu, and W. Bogaerts, IEEE J. Sel. Top. Quantum Electron. 19, 114 (2013).

2. R. Soref, IEEE J. Sel. Top. Quantum Electron. 12, 1678 (2006).

3. D. Chen, H. R. Fetterman, A. Chen, W. H. Steier, L. R. Dalton, W. Wang, and Y. Shi, Appl. Phys. Lett. 70, 3335 (1997).

4. X. Lin, T. Ling, H. Subbaraman, X. Zhang, K. Byun, L. J. Guo, and R. T. Chen, Opt. Lett. 38, 1597 (2013).

5. Y. Enami, C. T. Derose, D. Mathine, C. Loychik, C. Greenlee, R. A. Norwood, T. D. Kim, J. Luo, Y. Tian, A. Y. Jen, and N. Peyghambarian, Nat. Photon. 1, 180 (2007).

6. B. Bortnik, Y. C. Hung, H. Tazawa, B. J. Seo, J. Luo, A. K. Y. Jen, W. H. Steier, and H. R. Fetterman, IEEE J. Sel. Top. Quantum Electron. 13, 104 (2007).

7. M. Lee, H. E. Katz, C. Erben, D. M. Gill, P. Gopalan, J. D. Heber, and D. J. McGee, Science 298, 1401 (2002).

8. L. Thylen, U. Westergren, P. Holmström, R. Schatz, and P. Jänes, Opt. Fiber Telecommun. V., IP Kaminow 5, 183 (2008).

9. R. Palmer, S. Koeber, E. L. Delwin, M. Woessner, W. Heni, D. Korn, M. Lauermann, W. Bogaerts, L. Dalton, W. Freude, J. Leuthold, and C. Koos, J. Lightwave Technol. 32, 2726 (2014).

10. W. H. Steier, A. Chen, S. S. Lee, S. Garner, H. Zhang, V. Chuyanov, L. R. Dalton, F. Wang, A. S. Ren, C. Zhang, and G. Todorova, Chem. Phys. 245, 487 (1999).

11. T. Sun, L. Zhang, K. Receveur, A. K. Poddar, U. L. Rohde, and A. S. Daryoush, in IEEE MTT-S International Microwave Symposium (IMS 2015) (2015).

12. M. Hadjloum, M. El Gibari, H. Li, M. Halbwax, J. P. Vilcot, and A. S. Daryoush, in IEEE 2015 Microwave Photonics Meeting (MWP2015) (2015).

13. T. Baba, Nat. Photon. 2, 465 (2008).

14. H. C. Nguyen, S. Hashimoto, M. Shinkawa, and T. Baba, Opt. Express 20, 22465 (2012).

15. Y. A. Vlasov, M. O'Boyle, H. F. Hamann, and S. J. McNab, Nature 438, 65 (2005).

16. J. M. Brosi, C. Koos, L. C. Andreani, M. Waldow, J. Leuthold, and W. Freude, Opt. Express 16, 4177 (2008).

17. S. Inoue and A. Otomo, Appl. Phys. Lett. 103, 171101 (2013).

18. X. Zhang, C. J. Chung, A. Hosseini, H. Subbaraman, J. Luo, A. Jen, R. Neilson, C. Lee, and R. T. Chen, IEEE J. Lightwave Technol. 34, 2941 (2015).

19. Optiwave.s software OptiBPM, "Ansys HFSS," Version 12.2: http://ansys.com/, Capella Court, Ottawa (2016).

20. Ansoft's software of HFSS from Ansys, Inc., "Optiwave OptiBPM," Version 14.0: http://optiwave.com/, Ansys Drive, Canonsburg, PA (2016).

21. L. Zhang, A. K. Poddar, U. L. Rohde, and A. S. Daryoush, IEEE Photon. J. 6, 1 (2014). 